\title{
A Compact Printed Slot Antenna with High Out-of-band Rejection for WLAN/WiMAX Applications
}

\author{
Pichet MOEIKHAM ${ }^{1}$, Prayoot AKKARAEKTHALIN ${ }^{2}$ \\ ${ }^{1}$ Dept. of Electrical Engg., Faculty of Engineering, Rajamangala Univ. of Technology Lanna Chiang-Rai, Thailand, 57120 \\ ${ }^{2}$ Dept. of Electrical and Computer Engg., Faculty of Engineering, King Mongkut's Univ. of Technology North Bangkok, \\ Thailand, 10800
}

moei76@hotmail.com, prayoot@kmutnb.ac.th

Manuscript received September 1, 2015

\begin{abstract}
The suppression of electromagnetic interferences (EMIs) caused by the out-of-band operation is required for broadband antennas. To achieve this purpose, a compact broadband printed slot antenna with build-in filters for band notching is presented. The filters, including I-shaped and inverse L-shaped narrow slits and an L-shaped conductor strip, whose lengths correspond to half wavelengths, were integrated in the proposed antenna structure. The mitigation of the EMIs at the frequency ranges of 2.7 to $3.2 \mathrm{GHz}, 4.1$ to $4.7 \mathrm{GHz}$, and over $6.1 \mathrm{GHz}$ was obtained. The proposed antenna capably operated at WLAN/WiMAX frequency ranges of 2.26 to $2.68 \mathrm{GHz}, 3.28$ to $4.09 \mathrm{GHz}$, and 4.75 to $6.04 \mathrm{GHz}$. The nearly omni-directional and likely bi-directional radiation patterns were given by the proposed antenna in $x z$ and $y z$ planes, respectively. Therefore, this antenna is suitable for various WLAN/WiMAX applications.
\end{abstract}

\section{Keywords}

Printed slot antenna, multiband antenna, out-of-band rejection

\section{Introduction}

Modern wireless devices have the ability to support multi-standard operations, while their sizes must be small. As a result, compact wideband or multiband printed antennas are suitable and strongly required to support such devices. Obviously, the conventional printed antennas operate within a confined bandwidth. Many techniques are used to expand the operating bandwidth of printed antennas. For example, the curvature or taper structure was introduced to design the radiating elements in [1], [2], while an asymmetrical feeding line was also used in [3]. Due to the fact that modern wireless devices can support multi-standards occupying wideband or multiband frequency spectrums, the electromagnetic interference (EMI) appearance becomes a major problem. In order to mitigate the EMIs, printed broadband or ultra-wideband antennas with band notches are very attractive from a design perspective. Various techniques are employed for EMI reduction such as the uses of narrow slits, parasitic strips, and resonator techniques [3-11]. Although these printed monopole antennas have the ability to reduce EMIs, many antennas [3], [7-11] were designed by using both sides of the substrates. This may lead to complicated implementation, especially when used with other RF devices.

By determining the radiating elements and feeding parts separately, a higher degree of freedom for designing the printed slot antenna is given. Because of this, the printed slot antenna is very attractive for use with many wireless applications. Various shapes of both slots and feeding parts can be used to easily achieve broad bandwidth operations. For example, the trapezoid slot structures with various exciting stubs were employed to design printed slot antennas [12-14], resulting in extremely large impedance bandwidths. The semi-elliptic slot ground plane with a semi-ellipse patch was also proposed for wideband operation [15]. Additionally, slot antennas with notchedband in [16] were proposed using either narrow slits or strips for only single frequency rejection. Recently, the UWB antenna in [17] was designed using a narrow slit embedded into the exciting patch and an L-shaped shorting stub on the ground plane. However, all of these antennas used both metallic sides of the substrates, resulting in very complicated structures and high cost.

For general indoor wireless communications, WLAN is popular and is widely used. This system supports the IEEE $802.11 \mathrm{~b} / \mathrm{g} / \mathrm{a}$ standards. However, it cannot connect to broadband Internet directly. This weakness is solved by using the worldwide interoperability of microwave access (WiMAX) systems due to broadband Internet connecting ability. WiMAX is determined to operate with the IEEE802.16e standard, known as mobile WiMAX. Clearly, the operating frequency bands of 2.4 to $2.48 \mathrm{GHz}, 5.275$ to $5.375 \mathrm{GHz}$ and 5.725 to $5.85 \mathrm{GHz}$ are allocated for WLAN and 2.5 to $2.69 \mathrm{GHz}, 3.4$ to $3.7 \mathrm{GHz}$ and 5.15 to $5.85 \mathrm{GHz}$ are determined for WiMAX. It can be seen that these operating bands are close together and some bands overlap. All of the operating frequencies can be arranged into three bands: 2.4 to $2.69 \mathrm{GHz}, 3.4$ to $3.7 \mathrm{GHz}$ and 5.15 to $5.85 \mathrm{GHz}$. Therefore, an antenna must be designed to cover 
the entire bands of the WLAN/WiMAX operations. Recently, many multiband and wideband CPW-fed slot antennas have been proposed [18-21]. The antenna in [18] was designed using a parasitic line surrounding the fractal stub for undesired frequency rejection. This antenna is of a large size and it is difficult to control the notched bandwidth. The CPW-fed Koch fractal slot antenna with an embedded slot on the tuning stub was also proposed for dual band operation [19]. Due to the small space on the stub, the number of embedded slots is limited, resulting in narrow tuning ranges of the notch. In [20], the tri-band printed slot antenna for WLAN/WiMAX was proposed. This antenna used inverted-L strips to generate two resonant modes for wider bandwidth and the meandering split-ring slot on Y-shaped monopole to generate a band notch at $3 \mathrm{GHz}$. Again, due to the small space for the split-ring slot, the tuning for the notched band is very limited. Moreover, the higher operating bands of $5.275-5.375 \mathrm{GHz}$ and 5.15 to $5.85 \mathrm{GHz}$ are not covered for WLAN and WiMAX operations, respectively. It is clearly seen that the mentioned techniques could be employed to achieve notched bands for EMI reduction. However, using those techniques has the main disadvantages of narrow notched bands and limited notched frequency ranges. In order to overcome these problems, a combination of narrow slits and strips on the wideband slot antenna could be employed to reduce the EMIs on the out-of-band operations.

Therefore, this paper proposes a trapezoid slot antenna to achieve broad bandwidth. The feeding section is composed of a coplanar waveguide (CPW) transmission line with a characteristic impedance of $50 \Omega$ and a proper rectangle stub, which is used for exciting the resonant modes. The I-shaped and inverse L-shaped narrow slits in the ground plane and L-shaped conductor strip in the slot will be used to realize three notched bands. With the proposed techniques, the antenna has the ability to reduce the EMIs in three out-of-band operations and the notched bandwidths can easily be controlled. Additionally, the proposed antenna has a very simple geometry that can be easily fabricated on a single side of substrate, resulting in low cost. All of the details of the proposed antenna design, the parametric study, and the experimental validation of the prototype antenna will be presented in the following sections.

\section{Antenna Design}

In order to design and optimize the proposed antenna, CST software was employed. The designed antenna was on one metallic side of the FR4 substrate with a thickness of $1.6 \mathrm{~mm}$, with a dielectric constant of 4.4 , and a loss tangent of 0.019. The designed antenna evolution is shown in Figs. 1(a)-(d). All of the simulated results of $\left|S_{11}\right|$ are shown in Fig. 1 (e). The design procedures were as follows. First, the original printed slot antenna was designed, where the conductor ground plane area was determined to be $33 \times 33 \mathrm{~mm}^{2}$, as shown in Fig. 1 (a). The conductor ground plane was etched out with a trapezoid slot shape for broad- band impedance matching [21]. The $50 \Omega \mathrm{CPW}$ transmission line fed to a rectangle stub was used for exciting at the resonant frequencies. By optimizing the size of the exciting stub and its position, three resonant frequencies were generated. A broad bandwidth of $5.62 \mathrm{GHz}(2.38$ to $8 \mathrm{GHz})$ defined by the $\left|S_{11}\right| \leq-10 \mathrm{~dB}$ was obtained, as shown in Fig. 1(e). It was obviously seen that the first resonant frequency was the fundamental or dominant mode corresponding to the width of the slot and the third resonant frequency was its higher mode operation of the antenna. The second resonant frequency was obviously generated by the exciting stub. Clearly, the impedance bandwidth of the original antenna covered all of the WLAN/WiMAX frequency bands. However, the EMIs affecting the other wireless systems caused by the out-of-band operations at frequency ranges from 2.8 to $3.3 \mathrm{GHz}, 3.8$ to $5 \mathrm{GHz}$ and over $6 \mathrm{GHz}$ had to be mitigated. In order to remedy this problem, the frequency rejection had to be realized. Second, by embedding two pairs of narrow slits into the conductor ground plane, whose lengths corresponded to half guide wavelengths $\left(\lambda_{\mathrm{g}} / 2\right)$ of the rejected frequencies, two notched bands (2.8 to $3.3 \mathrm{GHz}$ and 3.8 to $5 \mathrm{GHz}$ ) were obtained. The length of each narrow slit $\left(l_{x}\right)$ was calculated from

$$
l_{x} \approx \frac{3 \times 10^{8}}{4 f_{\text {notch }} \sqrt{\frac{\varepsilon_{\mathrm{r}}+1}{2}}}
$$

In (1), $l_{x}$ is the length of the narrow slit, $f_{\text {notch }}$ is the rejected frequency, and $\varepsilon_{\mathrm{r}}$ is the dielectric constant of the substrate. The I-shaped narrow slits were embedded symmetrically on both sides of the slot in the conductor ground plane, where each length was set to be $13 \mathrm{~mm}$, as shown in Fig. 1(b). The notched band of $0.3 \mathrm{GHz}$ (2.9 to $3.2 \mathrm{GHz}$ ) at the resonant frequency of $3.17 \mathrm{GHz}$ was achieved as shown in Fig. 1(e). The overall length of the I-shaped narrow slits $(2 \times \mathrm{I} 1)$ was approximately a half guide wavelength at a frequency of $3.17 \mathrm{GHz}(26 \mathrm{~mm})$. In order to obtain the frequency rejection from 4 to $5 \mathrm{GHz}$, a pair of inverse L-shaped narrow slits was embedded into the conductor ground plane, as shown in Fig. 1(c). The length of each inverse L-shaped narrow slit (L1) was determined to be $9.5 \mathrm{~mm}$ using (1). Therefore, the overall length $(2 \times(\mathrm{L} 1+\mathrm{L} 3))$ was approximately a half guide wavelength at the resonant frequency of $4.6 \mathrm{GHz}(19 \mathrm{~mm})$. Although an antenna with two notched bands was obtained, the electromagnetic interference still appeared at frequencies higher than $6 \mathrm{GHz}$. Then, in order to reduce the energy emission in this band, a small L-shaped conductor strip with a length of a half guide wavelength at the rejected frequency was integrated and placed between the exciting stub and the border of the slot, as shown in Fig. 1(d). It was found that the frequency higher than $6 \mathrm{GHz}$ was rejected, as shown in Fig. 1(e). Therefore, the electromagnetic interference at this band was reduced. Additionally, the impedance matching of the third operation band was improved. It was clearly seen that the antenna in Fig. 1(d) provided three operation bands of 2.17 to $2.85 \mathrm{GHz}, 3.27$ to $4.1 \mathrm{GHz}$, and 4.8 to $6.1 \mathrm{GHz}$ covering the entire WLAN/ 
WiMAX bands and capably confined the out-of-band operations. Therefore, this antenna model was chosen. The geometry details and dimensions of the proposed antenna are shown in Fig. 1(f).

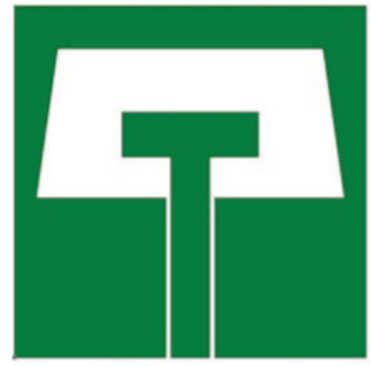

(a)

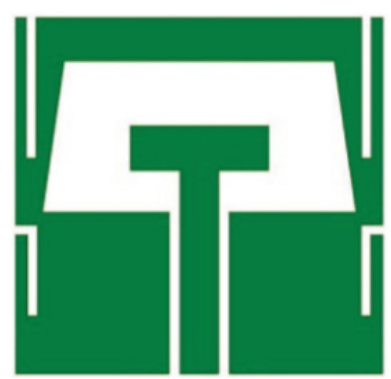

(c)

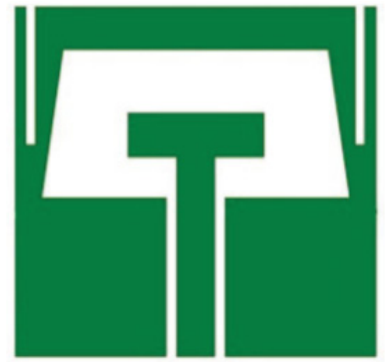

(b)

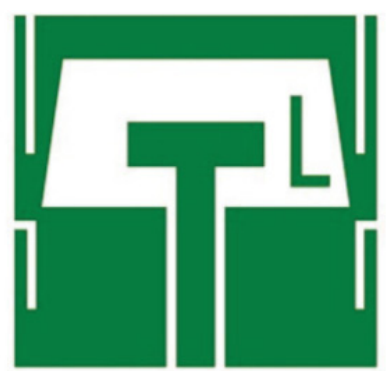

(d)

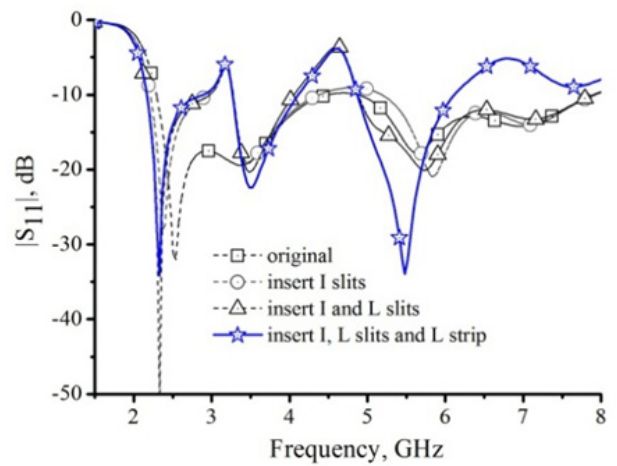

(e)

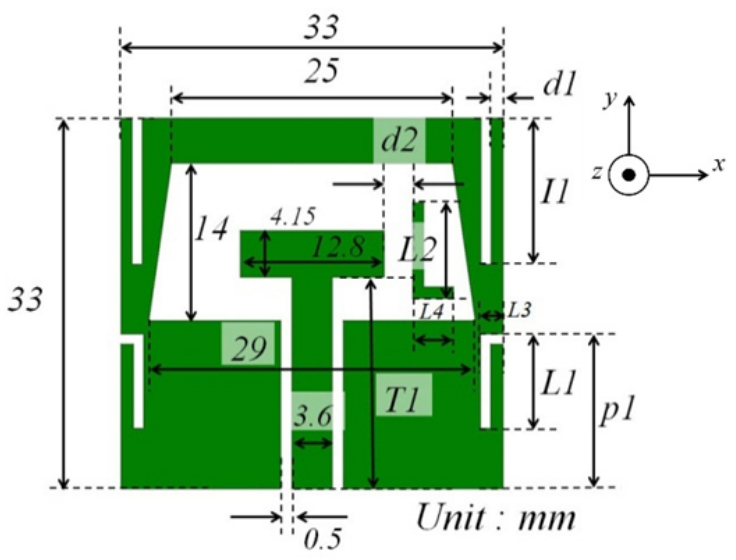

(f)

Fig. 1. The antenna structure: (a) original antenna, (b) with I-shaped slits, (c) with inverse L-shaped slits, (d) with L-shaped strip, (e) simulated results of all antennas, (f) geometry and dimension of the proposed antenna.

\subsection{Effect of Narrow Slits and Conductor Strip Length}

Three resonant frequencies with a broad impedance bandwidth from 2.38 to $8 \mathrm{GHz}$ were generated by the original antenna. In order to mitigate the EMIs caused by the out-of-band operation, I-shaped and inverse L-shaped narrow slits were embedded in the conductor ground plane and a small L-shaped conductor strip was placed in the slot. Even though undesired frequency rejection was achieved, these elements directly affected the antenna characteristics.

Therefore, the parametric studies of the mentioned elements were investigated by altering their lengths and positions, whereas other parameters were fixed. Figure 2(a) shows the $\left|\mathrm{S}_{11}\right|$ simulation results when the I1 parameter was altered. The results show that the resonance of the first rejected frequency altered from 3.4 to $3 \mathrm{GHz}$, while the I1 parameter varied from 12 to $14 \mathrm{~mm}$. The proper notched band of $0.3 \mathrm{GHz}$ (from 2.9 to $3.2 \mathrm{GHz}$ ) was obtained when the I1 parameter was set to be $13 \mathrm{~mm}$ and the overall length $(2 \times \mathrm{I1})$ was $26 \mathrm{~mm}$. The length was approximately a half wavelength, corresponding to (1). Although the varying of I1 had no effect on the first and third operation bands, there was a high effect on the impedance matching of the second band. When I1 parameter was decreased, the resonances of the rejected frequencies were generated close to the operating band of $3.5 \mathrm{GHz}$. The electromagnetic coupling between the exciting stub and the I-shaped narrow slits was increased. As a result, the impedance matching was worse. With a proper value of I1, the appropriate band notching and impedance matching of the second operating band were achieved.

Figure 2(b) shows the $\left|\mathrm{S}_{11}\right|$ simulation results when the length of the inverse L-shaped narrow slits denoted by L1 parameter was varied. The results show that the resonance of the second rejected frequency altered from 4.9 to $3.9 \mathrm{GHz}$ when $\mathrm{L} 1$ parameter was changed from 8.5 to $11.5 \mathrm{~mm}$. There was no effect on the first and third rejected frequencies. The notched band of $0.7 \mathrm{GHz}$ with a frequency range from 4.1 to $4.8 \mathrm{GHz}$ was obtained as $\mathrm{L} 1$ was set to be $9.5 \mathrm{~mm}$. The overall length of the inverse L-shaped narrow slits $(2 \times(\mathrm{L} 1+\mathrm{L} 3)=19.88 \mathrm{~mm})$ was approximately a half wavelength of the frequency of 4.6 GHz. There was no effect on the first operation band; however, there were high and moderate effects on the impedance matching of the second and third operation bands, respectively. However, when this rejected frequency band was generated close to the second or third operation band, the impedance matching of those bands became worse. This mismatching was caused by the increment of the electromagnetic coupling between the inverse L-shaped narrow slits and the radiating parts.

Figure 2(c) depicts the $\left|\mathrm{S}_{11}\right|$ simulation results when the length of the L-shaped conductor strip denoted by L2 parameter was altered from 10.15 to $13.15 \mathrm{~mm}$. The results show that when L2 parameter was decreased, the resonance of the third rejected frequency slightly moved from 6.125 to $7.15 \mathrm{GHz}$. As a result, the upper edge frequency of the third operation band gradually increased and vice versa. 


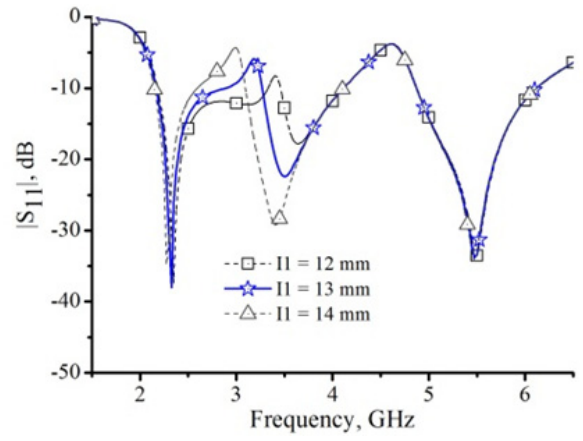

(a)

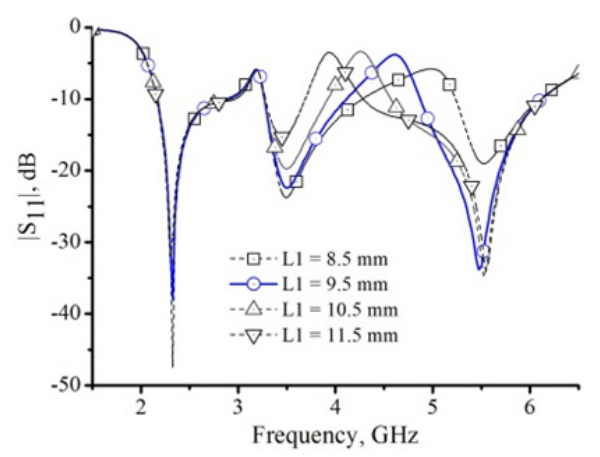

(b)

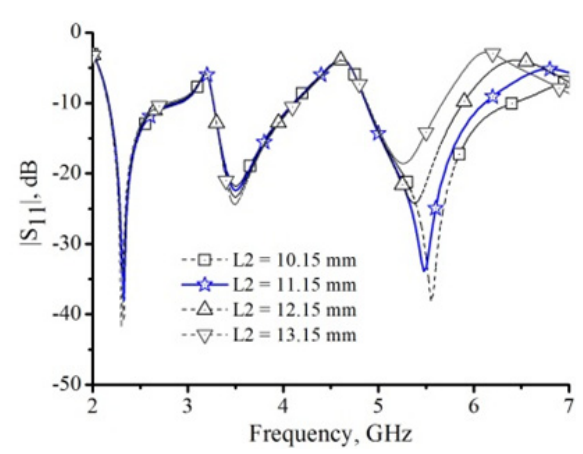

(c)

Fig. 2. Simulated results of parameter studies when varying of (a) I1, (b) L1, and (c) L2.

Additionally, the impedance matching of this operation band was also improved when L2 was decreased due to the decrement of the electromagnetic coupling between the exciting stub and the L-shaped conductor strip. The proper length of L2 parameter of $11.15 \mathrm{~mm}$ provided the third operation band covering 4.8 to $6.1 \mathrm{GHz}$ suitable for WLAN/WiMAX systems. There was no effect on the other operation bands. The overall length (L2+L4) was approximately a half wavelength of the rejected frequency of $6.8 \mathrm{GHz}$ corresponding to (1).

\subsection{Position of Narrow Slits and Conductor Strip}

As mentioned, the rejected frequencies and notched bandwidths of the proposed antenna were varied with the lengths of the narrow slits and conductor strip. However, their positions also affected the antenna characteristics. Figure 3(a) illustrates the simulated results when the position of the I-shaped narrow slits, denoted by $\mathrm{d} 1$ parameter, was varied. It was found that this parameter had greater effects on the first notched band but there were no effects on the others. It was also seen that when $\mathrm{d} 1$ parameter was increased, the notched bandwidth increased due to the increment of the electromagnetic coupling between the radiating parts and the narrow slits and vice versa. Additionally, while $\mathrm{d} 1 \mathrm{was}$ increased, the center of the rejected frequency slightly shifted to lower a frequency and the impedance matching of the second operation band gradually worsened. Further, the first resonant frequency was slightly shifted to a lower band and vice versa. By adjusting the proper value of $\mathrm{d} 1$ parameter, the appropriate notched band of $0.35 \mathrm{GHz}$ (2.9 to $3.25 \mathrm{GHz}$ ) was achieved.

Figure 3(b) depicts the simulated $\left|\mathrm{S}_{11}\right|$ whereas the position of the narrow inverse L-shaped slits, denoted by $\mathrm{p} 1$ parameter, was altered. It was seen that there was little effect on the second notched band. When $\mathrm{p} 1$ parameter was increased, the entire notched bands slightly moved to higher frequencies and vice versa. There was little effect on the impedance matching of any of the operation bands. The simulation results when the distance between the exciting stub and L-shaped conductor strip denoted by $\mathrm{d} 2$ parameter varied, as shown in Fig. 3(c). The results show that when the L-shaped conductor strip was moved far away from the exciting stub, the third rejected frequency $(>6 \mathrm{GHz})$ moved up. As a result, the upper edge of the third operation band slightly shifted to a higher frequency and vice versa. This was due to the increment of the electromagnetic coupling between the radiating part and the L-shaped conductor strip and vice versa. The optimal $\mathrm{d} 2$ parameter of $3 \mathrm{~mm}$ provided the proper upper edge of the third band. There were no effects on the other operation bands.

Figure 3(d) depicts the simulation results whereas the height of the exciting stub denoted by $\mathrm{T} 1$ parameter was altered. The results show that the increment of $\mathrm{T} 1 \mathrm{can}$ improve the impedance matching of the first and third operation bands simultaneously and vice versa. The contrary effect occurred for the second band. It was obvious that the impedance matching of the printed slot antenna was controlled by the exciting stub. Additionally, when T1 was increased, the resonant frequency of the second operation band slightly shifted to a lower frequency and vice versa. This is due to the exciting stub acting as the major radiation part of this band.

\subsection{Current Distributions}

For greater understanding of the antenna operation and the limitation of the EMIs, the vector surface current distributions were simulated as shown in Fig. 4. Figures 4(a) to (c) display the vector surface current distributions along the conductor around the slot, which is the main radiator. At the frequency of $2.35 \mathrm{GHz}$, the vector current distribution strongly concentrated around the slot, as shown in Fig. 4(a). The current paths generated the fundamental resonant frequency or dominant mode. Each path length was approximately a half guide wavelength. Additionally, the higher mode operation of the antenna occurred at the frequency of $5.5 \mathrm{GHz}$ The vector current was distributed 


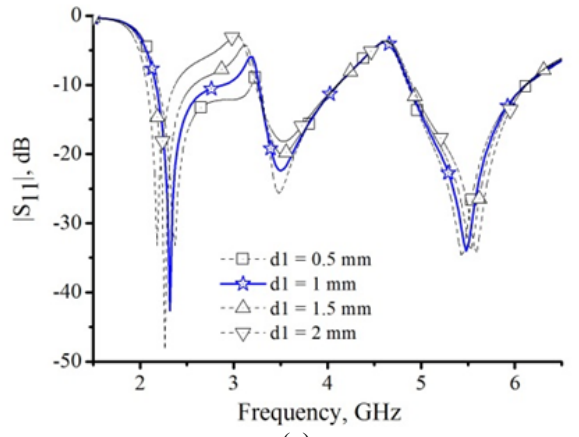

(a)

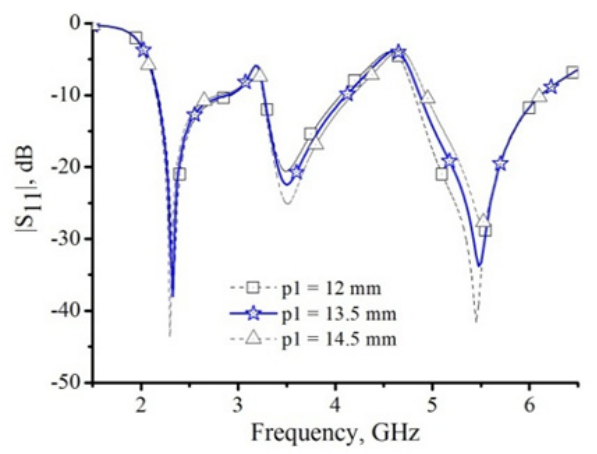

(b)

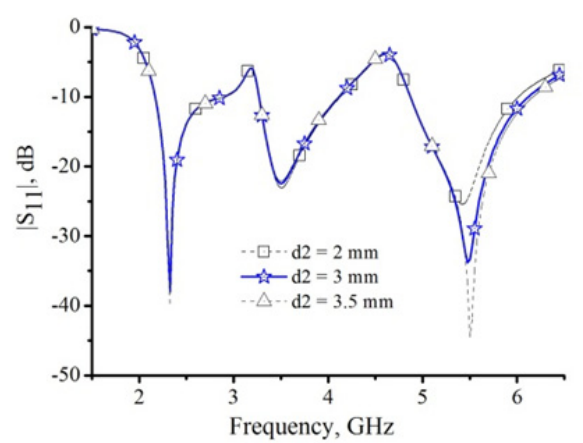

(c)

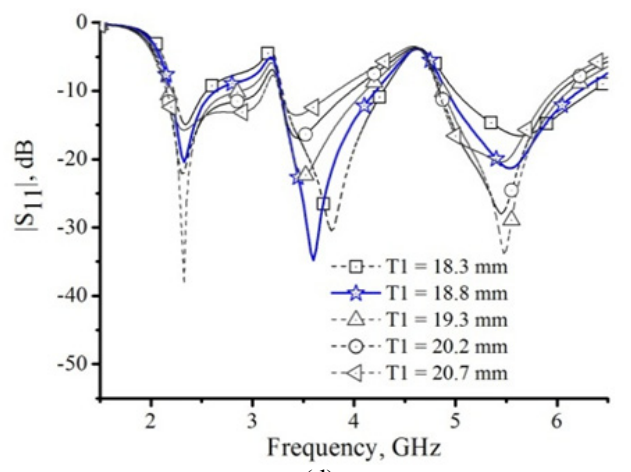

(d)

Fig. 3. Simulated results of parameter studies when varying (a) d1, (b) p1, (c) d2, and (d) $\mathrm{T} 1$.

around slot with a periodic of a half path of the dominant mode, where the current strongly concentrated nearly four corners of the slot, as shown in Fig. 4(c). Figure 4(b) depicts the vector current distribution at the frequency of $3.5 \mathrm{GHz}$. It was seen that the vector current concentrated at the lower edge of the exciting stub acting as the main radiator at this frequency. This current path was approximately a half guide wavelength of the resonant frequency.

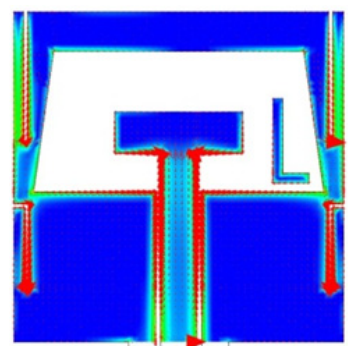

(a)

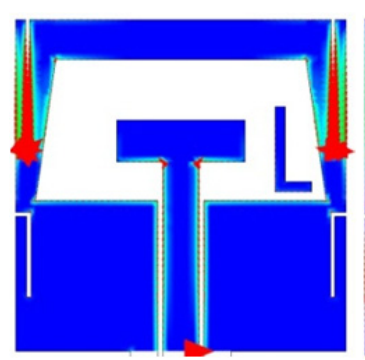

(c)

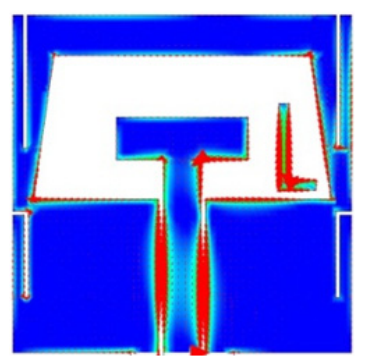

(e)

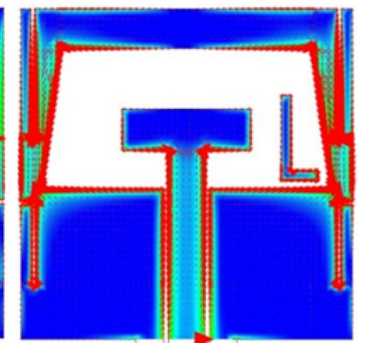

(b)

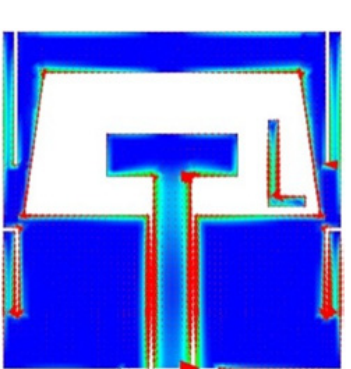

(d)

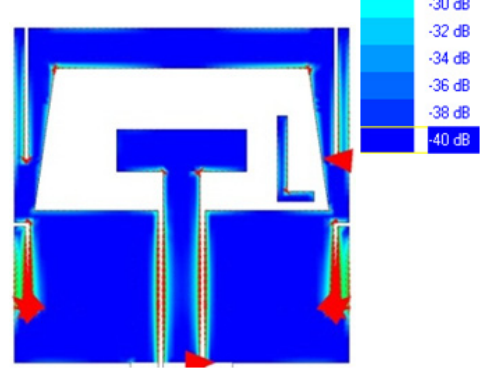

(f)
Fig. 4. Simulated results of surface current distribution at frequencies (a) $2.35 \mathrm{GHz}$, (b) $3.5 \mathrm{GHz}$, (c) $5.5 \mathrm{GHz}$, (d) $3.1 \mathrm{GHz}$, (e) $4.6 \mathrm{GHz}$, and (f) $6.8 \mathrm{GHz}$.

The simulated vector surface current distributions at the resonances of rejected frequencies of 3.1, 4.6 and $6.8 \mathrm{GHz}$ are displayed in Figs. 4(d) to (f), respectively. In Fig. 4(d), at $3.1 \mathrm{GHz}$ it was found that the vector current distribution strongly concentrated only at the I-shaped narrow slits, meanwhile there were little current distribution at the other parts. On the other hand, almost all energy was absorbed or stored by the I-shaped narrow slits. Therefore, the antenna cannot radiate at this frequency. The limitation of the emission from the antenna was obtained. At frequencies of $4.6 \mathrm{GHz}$ and $6.8 \mathrm{GHz}$, it was seen that the vector current distributions strongly concentrated only on the inverse L-shaped slits and L-shaped conductor strip as shown in Figs. 4(e) and (f), respectively. Most of the energy was absorbed by these parts, whereas a little vector current leaked to the others. As a result, the antenna cannot radiate power. Therefore, the frequency rejections at 4.6 and $6.8 \mathrm{GHz}$ were obtained. Further, the EMI mitigation of these bands was achieved.

\section{Implementation and Measurement}

All of the optimal parameters from the simulation were employed to fabricate the prototype antenna using a single metallic side on the FR4 substrate, as shown in 
Fig. 5(a). Photolithographic and chemical wet etching methods were used. For the purpose of measurement, the SMA connector was applied. A comparison $\left|\mathrm{S}_{11}\right|$ between the simulation and the measurement results is shown in Fig. 5(b). It was found that the measured results showed little discrepancy due to the discontinuity between the SMA connector and the CPW feeding line and fabrication tolerance. The measured results showed that the first band slightly shifted to a higher frequency when compared with the simulation. The measured frequency range was from 2.26 to $2.68 \mathrm{GHz}$. Although the second band seemed to coincide with simulated results, two resonant frequencies occurred owing to the two current paths on the conductor at the lower edge of the slot and on the exciting stub, as seen in Fig. 4(b). The second operation band with a bandwidth of $0.81 \mathrm{GHz}$ or the frequency range of 3.28 to $4.09 \mathrm{GHz}$ was obtained using the prototype antenna. For the third band, it was seen that the resonant frequency shifted to $5 \mathrm{GHz}$ with the frequency range covering $4.75 \mathrm{GHz}$ to 6.04 GHz. This was adequate for use with the higher bands of the WLAN/WiMAX systems. It was proved that the prototype antenna provided three impedance bandwidths covering the entire operating frequency bands of the WLAN/WiMAX systems.

Comparisons between the simulated and measured radiation pattern results in $x z$ and $y z$ planes are shown in Figs. 6 and 7, respectively. The simulated and measured co-polarization results are denoted by solid lines with symbols, whereas all of the cross-polarization results are denoted by a solid line with crossed symbols in $x z$ plane at frequencies of 2.5, 3.5 and 5.5 GHz, as shown in Figs. 6(a), (b) and (c), respectively. It was found that the measured copolarization provided nearly omni-directional patterns at all frequencies. A little distortion could be found due to the inevitable disturbance of the signal emission from the connectors. Additionally, high cross-polarizations were generated at all frequencies due to the surface current vector flows along the radiating paths in different directions. Figures 7(a), (b) and (c) show the comparisons of the simulated and measured radiation results in yz plane. The measured co-polarization results showed likely bi-directional radiation patterns at all frequencies, although some distortions were found at a frequency of $3.5 \mathrm{GHz}$. Additionally, high cross-polarizations were also found.

A broadside gain measurement was set up by placing two identical prototype antennas with a distance of $35 \mathrm{~cm}$. The measurement was then performed using a network analyzer. A comparison of the broadside gain between the measured and simulated results showed good agreement, as shown in Fig. 8. It was seen that the first band showed a coincidence with both results. At the second and third bands, there were slight discrepancies, where the measured result showed a higher broadside gain than the simulated result. According to the measurement, the average broadside gains of the antenna were $1.67 \mathrm{dBi}, 2.75 \mathrm{dBi}$ and $5.5 \mathrm{dBi}$ at the first, second, and third operation bands, respectively.

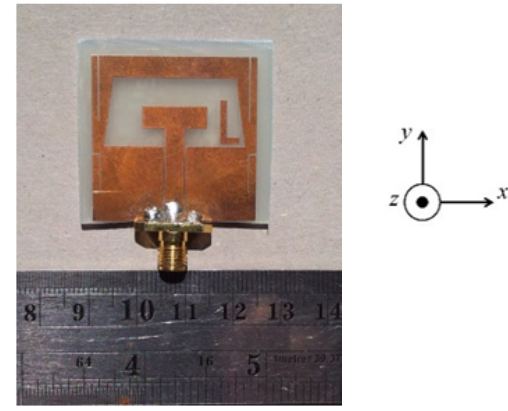

(a)

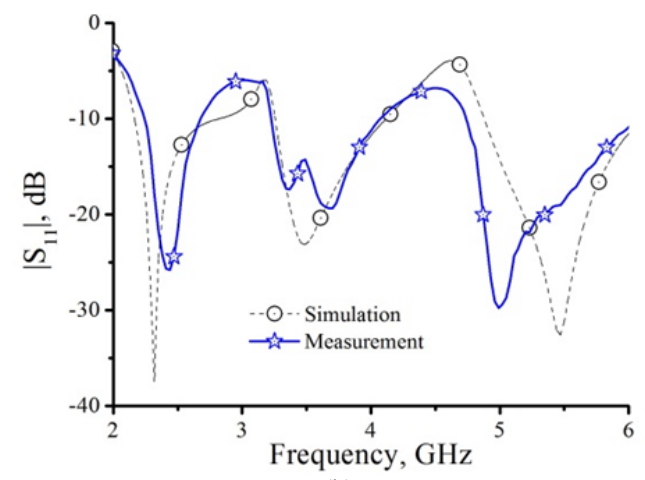

(b)

Fig. 5. (a) The prototype antenna and (b) comparison of simulated and measured $\left|\mathrm{S}_{11}\right|$.

\section{Conclusions}

In this paper, a broadband slot antenna with narrow slits and a small conductor strip has been proposed so that the undesired frequencies could be rejected, resulting in EMI mitigation. The first two rejected frequency bands were capably controlled by the length of the narrow slits corresponding to approximately a half guide wavelength. Also, a small half guide wavelength conductor strip placed in the slot was used to control the third band. By determining the proper lengths and positions of the added elements, the proposed antenna was able to reduce the EMIs and provide triple band operation with frequency ranges from 2.26 to $2.68 \mathrm{GHz}, 3.28$ to $4.09 \mathrm{GHz}$ and 4.75 to $6.04 \mathrm{GHz}$ covering all WLAN/WiMAX frequencies. The presented antenna has nearly omni-directional and likely bi-directional radiation patterns in $x z$ and $y z$ planes, respectively. It was proved that the proposed antenna is a good candidate to be used for WLAN/WiMAX applications.

\section{Acknowledgments}

The authors would like to acknowledge the Faculty of Engineering, Rajamangala University of Technology Krungthep for the antenna measurement. This work has been supported by the Thailand Research Fund through the TRF Senior Research Scholar Program with Grant No. RTA5780010. 


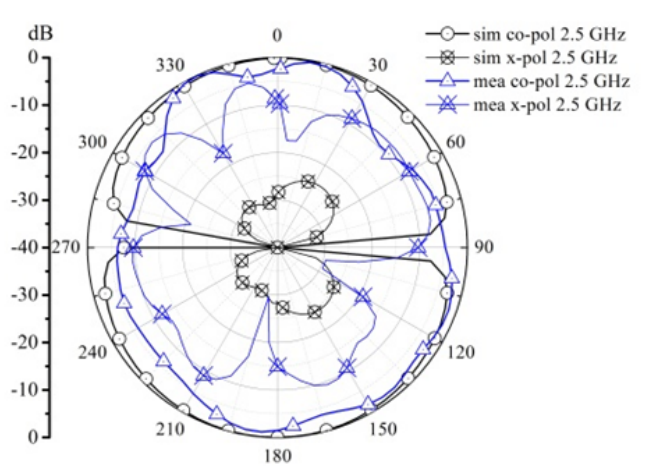

(a)

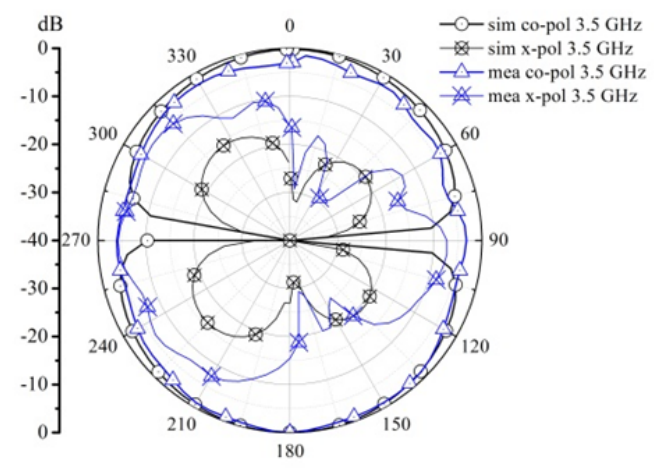

(b)

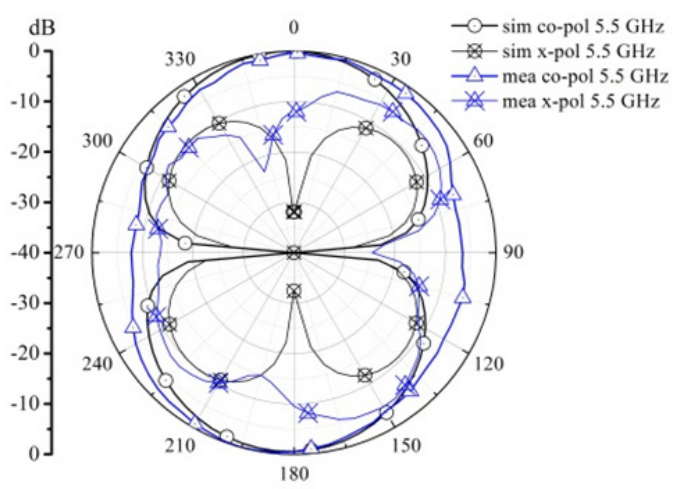

(c)

Fig. 6. Radiation pattern results in $x z$ plane (a) $2.5 \mathrm{GHz}$, (b) $3.5 \mathrm{GHz}$, and (c) $5.5 \mathrm{GHz}$.

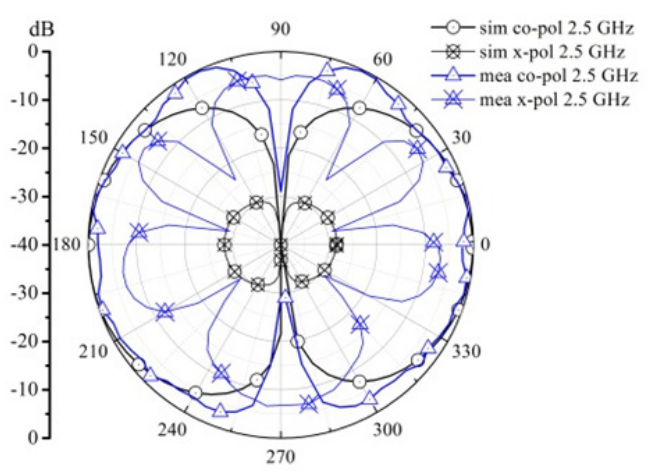

(a)

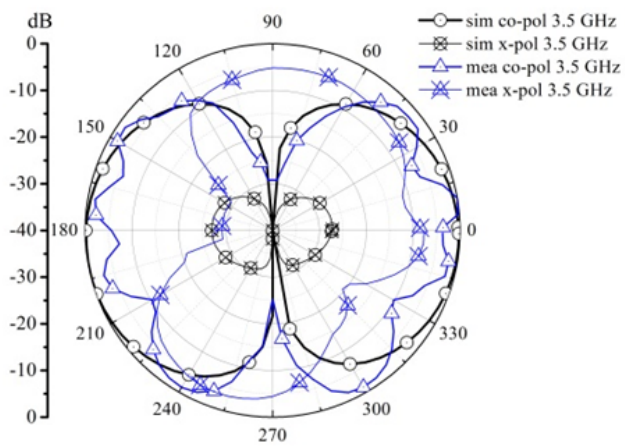

(b)

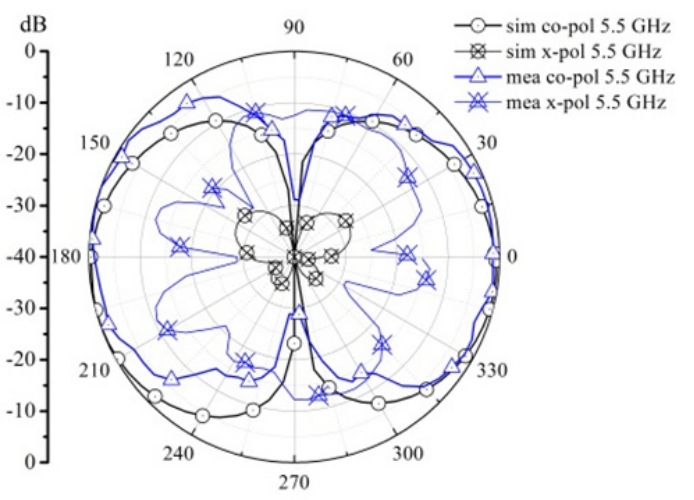

(c)

Fig. 7. Radiation pattern results in $y z$ plane (a) $2.5 \mathrm{GHz}$, (b) $3.5 \mathrm{GHz}$, and (c) $5.5 \mathrm{GHz}$.

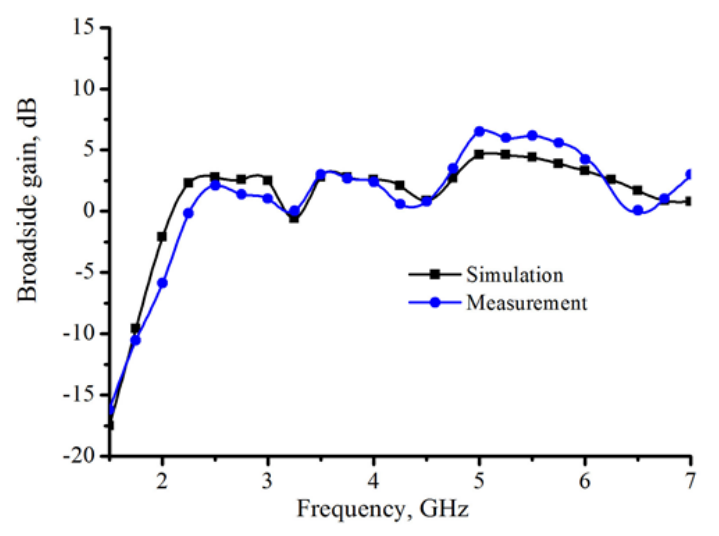

Fig. 8. A comparison result of simulated and measured broadside gains.

\section{References}

[1] ZAKER, R., GHOBADI, CH., NOURINIA, J. A modified microstrip-fed two-step tapered monopole antenna for UWB and WLAN applications. Progress In Electromagnetics Research, 2007, PIER 77, p. 137-148. DOI: 10.2528/PIER07080701

[2] MOEIKHAM, P., AKKARAEKTHALIN, P. A compact ultrawideband monopole antenna with tapered CPW feed and slot stubs. In Proceedings of the ${ }^{\text {th }}$ International Conference of Electrical Engineering/Electronics, Computer, Telecommunications and Information Technology (ECTI-CON). Khon Kaen (Thailand), 2011, p. 180-183, 2011. DOI: 10.1109/ECTICON.2011.5947802 
[3] ISLAM, M. T., AZIM, R., MOBASHSHER, A. T. Triple bandnotched planar UWB antenna using parasitic strips. Progress In Electromagnetics Research, 2012, vol. 129, p. 161-179. DOI: 10.2528/PIER12032604

[4] ZHANG, X., ZHANG, T.-L., XIA, Y.-Y., YAN, Z.-H., WANG, X.-M. Planar monopole antenna with band-notch characterization for UWB applications. Progress In Electromagnetics Research Letters, 2009, vol. 6, p. 149-156. DOI: 10.2528/PIERL09011305

[5] TRANG, N. D. , LEE, D. H., PARK, H. C. Compact printed CPWfed monopole ultra-wideband antenna with triple subband notched characteristics. Electronics Letters, 2010, vol. 46, no. 17, p. 1177 to 1179 . DOI: $10.1049 / \mathrm{el} .2010 .1140$

[6] MOEIKHAM, P., MAHATTHANAJATUPHAT, C., AKKARAEKTHALIN, P. A compact ultrawideband monopole antenna with $\mathrm{V}$-shaped slit for $5.5 \mathrm{GHz}$ notched band. In Proceedings of the $9^{\text {th }}$ International Conference of Electrical Engineering/Electronics, Computer, Telecommunications and Information Technology (ECTI-CON). Hua Hin (Thailand), 2012. DOI: 10.1109/ECTICon.2012.6254176

[7] LI, W.-M., NI, T., QUAN, T., JIAO, Y.-C. A compact CPW-fed UWB antenna with WiMAX-band notched characteristics. Progress In Electromagnetics Research Letters, 2011, vol. 26, p. 79-85. DOI: 10.2528/PIERL11080202

[8] MOEIKHAM, P., MAHATTHANAJATUPHAT, C., AKKARAEKTHALIN, P. A compact ultrawideband monopole antenna with $5.5 \mathrm{GHz}$ notched band. Progress In Electromagnetics Research C, 2012, vol. 26, p. 13-27. DOI: 10.2528/PIERC11091602

[9] MOEIKHAM, P., MAHATTHANAJATUPHAT, C., AKKARAEKTHALIN, P. A compact UWB antenna with a quarterwavelength strip in a rectangular slot for $5.5 \mathrm{GHz}$ band notch. International Journal of Antennas and Propagation, vol. 2013, Article ID 574128, 9 pages. DOI: 10.1155/2013/574128

[10] WU, S.-J., TARNG, J.-H. Planar band-notched ultra-wideband antenna with square-looped and end-coupled resonator. IET Microwave, Antennas and Propagation, 2011, vol. 5, p. 1227 to 1233. DOI: 10.1049 /iet-map.2010.003

[11] WU, S.-J., KANG, C.-H., CHEN, K.-H., et al. Study of an ultrawideband monopole antenna with a band- notched open- looped resonator. IEEE Transactions on Antennas and Propagation, 2010, vol. 58, no. 6, p. 1890-1897. DOI: 10.1109/TAP.2010.2046839

[12] MOEIKHAM, P., AKKARAEKTHALIN, P. Printed slot antenna for WLAN/WiMAX and UWB applications. In International Symposium on Antennas and Propagation (ISAP 2013). Nanjing (China), 2013, p. 88-91.

[13] MOEIKHAM, P., TANGTHONG, N., AKATIMAGOOL, S. CPW-fed printed slot antenna for WLAN/WiMAX and UWB applications. In International Symposium on Antennas and Propagation (ISAP). Kaohsiung (China), 2014, p. 227-228. DOI: 10.1109/ISANP.2014.7026613

[14] CHEN, D., CHENG, C. H. A novel compact ultra-wideband (UWB) wide slot antenna with via holes. Progress In Electromagnetics Research, 2009, vol. 94, p. 343-349. DOI: 10.2528/PIER09062306

[15] GOPIKRISHNA, M., DEEPTI DAS KRISHNA, C. K. ANANDAN, C. K., MOHANAN, P., VASUDEVAN, K. Design of a compact semi-elliptic monopole slot antenna for UWB systems. IEEE Transactions on Antennas and Propagation, 2009, vol. 57, no. 6, p. 1834-1837. DOI: 10.1109/TAP.2009.2015850

[16] LIN, Y. C., HUNG, K. J. Compact ultrawideband rectangular aperture antenna and band-notched designs. IEEE Transactions on
Antennas and Propagation, 2006, vol. 54, no. 11, p. 3075-3081. DOI: 10.1109/TAP.2006.883982

[17] GAO, P., XIONG, L., DAI, J., HE, S., ZHENG, Y. Compact printed wide-slot UWB antenna with $3.5 / 5.5-\mathrm{GHz}$ dual bandnotched characteristics. IEEE Antennas and Wireless Propagation Letters, 2013, vol. 12, p. 983-986. DOI: 10.1109/LAWP.2013.2277591

[18] HONGNARA, T., MAHATTANAJATUPHAT, C., AKKARAEKTHALIN, P. A multiband CPW-fed slot antenna. Radioengineering, 2012, vol. 21, no. 2, p. 597-605.

[19] KRISHNA, D.D., GOPIKRISHNA, M., ANANDAN, C. K. MOHANAN, P., VASUDEVAN, K. CPW-fed Koch fractal slot antenna for WLAN/WiMAX applications. IEEE Antennas and Wireless Propagation Letters, 2008, vol. 7, p. 389-392. DOI: 10.1109/LAWP.2008.2000814

[20] LIU, P., ZOU, Y., XIE, B., LIU, X., SUN, B. Compact CPW-fed tri-band printed antenna with meandering split-ring slot for WLAN/WiMAX applications. IEEE Antennas and Wireless Propagation Letters, 2012, vol. 11, p. 1242-1244. DOI: 10.1109/LAWP.2012.2225402

[21] BALANIS, C. Antenna Theory, Analysis and Design. 3rd ed. Hoboken (NJ, USA): John Wiley \& Sons, 2005. ISBN: 978-0-47166782-7

\section{About the Authors ...}

Pichet MOEIKHAM received the M.Eng. degree in Electrical Engineering from Rajamangala University of Technology, Thanyaburi (RMUTT) in 2008 and the Ph.D. degree in Electrical Engineering from King Mongkut's University of Technology, North Bangkok (KMUTNB), Thailand, in 2013. He currently works as a lecturer in the Department of Electrical Engineering, Faculty of Engineering, Rajamangala University of Technology Lanna (RMUTL), Chiang-Rai, Thailand. His research interests include wideband and multiband antennas, and telecommunication applications.

Prayoot AKKARAEKTHALIN (corresponding author) was born in Nakorn Pathom, Thailand. He received the B.Eng. and M.Eng. degrees in Electrical Engineering from King Mongkut's University of Technology, North Bangkok (KMUTNB), Thailand in 1986 and 1990, respectively, and the Ph.D. degree from the University of Delaware, Newark, USA, in 1998. From 1986 to 1988, he worked at Microtek Co. Ltd., Thailand as a microwave research and development engineer. In 1988, he joined the Department of Electrical Engineering at KMUTNB as an instructor. His current research interests include passive and active microwave circuits, wideband and multiband antennas, and telecommunication systems. Dr. Prayoot is a member of IEEE, IEICE Japan, and ECTI Thailand. He was Chairman of the IEEE MTT/AP/ED Thailand Joint Chapter during 2007 and 2008 and President of ECTI Association from 2014 to 2015. He is currently the head of the TRF Senior Research Scholar Project of the Thailand Research Fund. 